\title{
Reverse Phase Chromatographic Method of Analysis for Assay and Content Uniformity Estimation of Drug Sitagliptin, Metformin and Empagliflozin from Available Marketed Formulation
}

\author{
GOPAL MOHANRAO KADAM ${ }^{1}$, AVINASH LAXMANRAO PUYAD ${ }^{1 *}$, TUKARAM \\ MOHANRAO KALYANKAR ${ }^{2}$ and RAJESHWAR VISHWANATH KSHIRSAGAR ${ }^{2}$
}

\author{
${ }^{1}$ School of Chemical Sciences, S.R.T.M. University, Nanded-431606, India. \\ ${ }^{2} S c h o o l$ of Pharmacy, S.R.T.M. University, Nanded-431606, India. \\ *Corresponding author E-mail: avinashlpuyad@gmail.com
}

http://dx.doi.org/10.13005/ojc/370424

(Received: June 04, 2021; Accepted: July 05, 2021)

\begin{abstract}
A new method of analysis with reverse phase chemistry was designed and developed. Validation for method of analysis was performed for its intended use to calculate assay and content uniformity of drug substance sitagliptin, metformin and empagliflozin in the drug products. The method has a run time of $10 \mathrm{~min}$ on X-bridge $\mathrm{C} 18$ column having $250 \mathrm{~mm}$ length, $4.6 \mathrm{~mm}$ internal diameter and Particle Size of $5 \mu \mathrm{m}$, by the use of $0.1 \%$ Trifluoroacetic acid Buffer $40 \%$ : Methanol $40 \%$ : Acetonitrile $20 \%$ ratio as constituent composition in the proposed mobile phase and chromatography run at wavelength of $224 \mathrm{~nm}$. The retention time of Metformin, Empagliflozin and Sitagliptin, were $3.383,5.571$ and 6.429 min respectively. International Conference on Harmonization guideline was referred for validation. The method showed adequate sensitivity for precision, linearity and accuracy parameter (between the range $25-75 \mu \mathrm{g} / \mathrm{mL}, 250-750 \mu \mathrm{g} / \mathrm{mL}$ and 2.5-7.5 $\mu \mathrm{g} / \mathrm{mL}$ for sitagliptin, metformin and empagliflozin respectively). The percentage recoveries obtained for sitagliptin, metformin and empagliflozin are in the range of 98.0-102.0\%. As results are within the acceptance ${ }^{1}$, hence the new developed and proposed method is suitable for quantification of one, two or three component drugs, separately or in combination.
\end{abstract}

Keywords: Sitagliptin, Metformin, Empagliflozin, RP-HPLC, Content Uniformity.

INTRODUCTION

Sitagliptin, metformin drugs are used to treat type 2 diabetes health issues, along with diet, exercise, and for overweight patients either alone or in combination with other types of oral hypoglycemic agents and empagliflozin drug is used in patients having type 2 diabetes along with diet and exercise. The drugs are taken either single or in combination with each other and are taken orally ${ }^{2-3}$.

The chemical structures of sitagliptin, metformin and empagliflozin are as follows:

This is an Open Access article licensed under a Creative Commons license: Attribution 4.0 International (CC- BY). Published by Oriental Scientific Publishing Company @ 2018

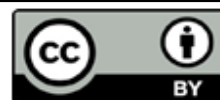


<smiles>N[C@@H](CC(=O)N1CCn2c(nnc2C(F)(F)F)C1)Cc1cc(F)c(F)cc1F</smiles>

Fig. 1. Representing the Structure of Sitagliptin

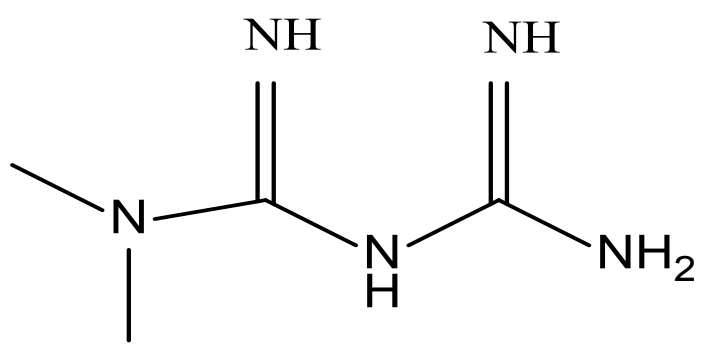

Fig. 2. Representing the Structure of Metformin<smiles>OC[C@H]1O[C@@H](c2ccc(Cl)c(Cc3ccc(O[C@H]4CCOC4)cc3)c2)[C@H](O)[C@H](O)[C@@H]1O</smiles>

Fig. 3. Representing the Structure of Empagliflozin

Initially, trials were taken to optimize an analytical method for metformin and empagliflozin. A method of analysis with reversed-phase chemistry using high-performance liquid chromatographic instrument was designed to develop and calculate contents of metformin and empagliflozin by using INNO C18 column (4.6 $\mathrm{mm}$ internal diameter with $150 \mathrm{~mm}$ length and particle size of $5 \mu \mathrm{m}$ ). The constituents in mobile phase mixture are $\mathrm{pH} 3.0$ phosphate buffer $30 \%$ and methanol $70 \%$ ratio at a constant flow in the instrument i.e. $1.0 \mathrm{~mL} / \mathrm{min}$ and injection volume of $10 \mu \mathrm{L}$ in the waters manufactured HPLC, with auto sampler and type of separation module 2695, with PDA detector 2996. Results for the developed method showed that there are no interfering peaks from blank solution at the specified retention time of metformin and empagliflozin. Retention time for metformin was observed at about 1.8 minute with tailing factor of not more than 2.0 \& plate counts of more than 2000 and for empagliflozin was observed at about 2.7 min with tailing factor not more than 2.0 \& plate counts of more than 2000. A specific and simple RP-HPLC method was developed. As, metformin \& empagliflozin are available in marketed formulation in single as well as in different combinations as empagliflozin tablets, metformin tablets, empagliflozin \& metformin tablets, sitagliptin \& metformin tablets. Hence, the research further continued by including one more drug substance sitagliptin. The aim was to achieve novelty in research by developing a new method for assay \& content uniformity test for multicomponent analysis of drugs and for two tests (Assay and content uniformity).

Review of literature study done for development of a new method ${ }^{4-10}$. From the literature study ${ }^{11-19}$ as tabulated in Table 1, it is observed that there are few methods available only for assay test determination of single or two drug components and single method for assay and content uniformity test is not available. To the best of our knowledge, it was observed that a single method to estimate three drug components for two tests i.e., assay and content uniformity (content of single dosage unit) test to estimate and calculate the drug substance sitagliptin, metformin and empagliflozin in the marketed drug product is not available. Hence, the research work was initiated for development and to validate a new, simple, accurate and economical method by RP-HPLC equipped with PDA detector. Sample preparation, diluent, and mobile phase in the proposed method is easy to prepare and economical and this method of analysis can be used for routine determination and calculation of drug components as well as to estimate stability batches analysis in quality control and research laboratory for assay and content uniformity calculation of drug substance sitagliptin, metformin and empagliflozin in available marketed drug product.

\section{Method development trials}

Trials were performed to optimize a new HPLC method for multicomponent analysis and are summarized in below Table 2. Chromatograms are shown in Figure 4 \& 5. 
Table 1: Summary of method development trials

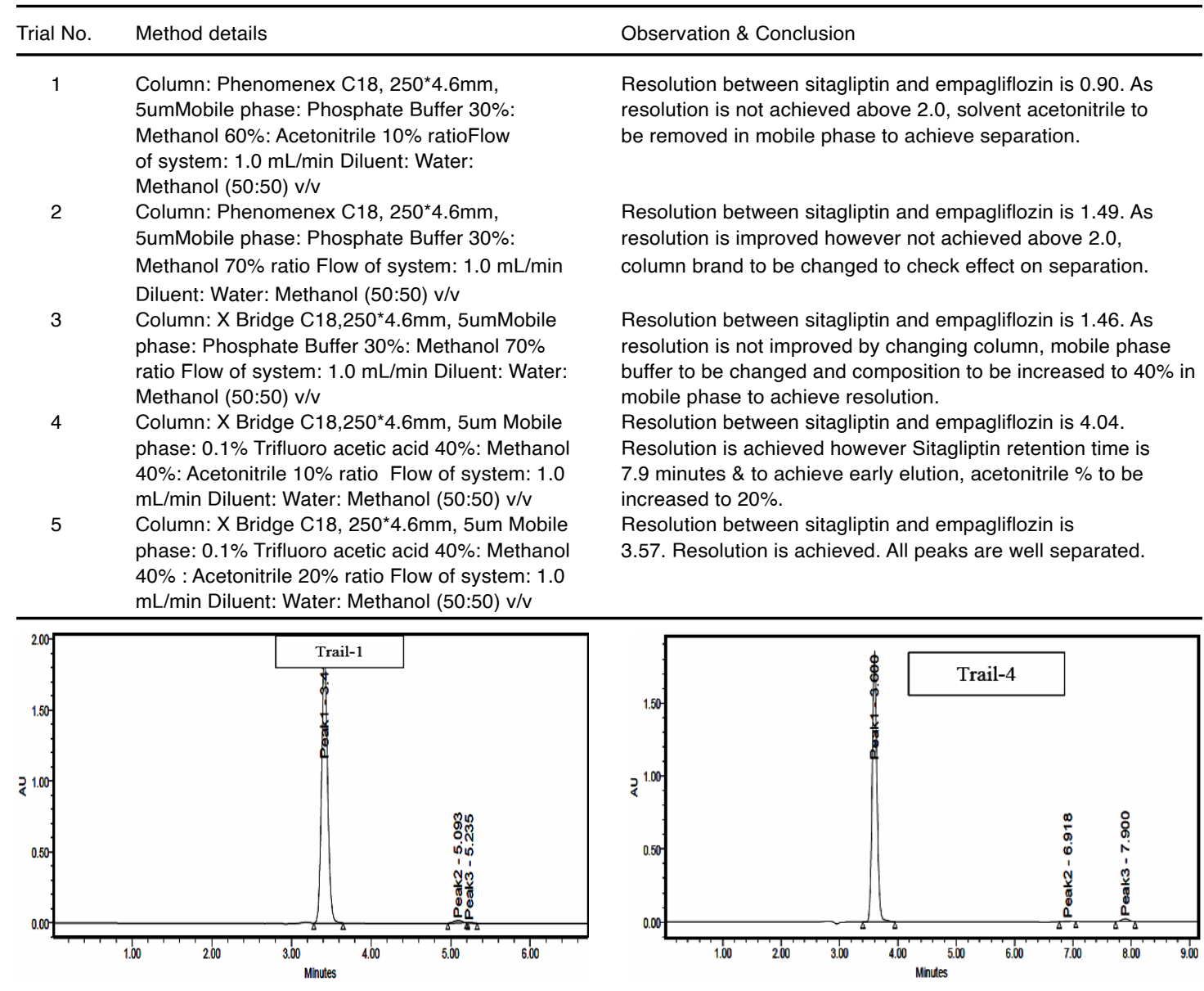

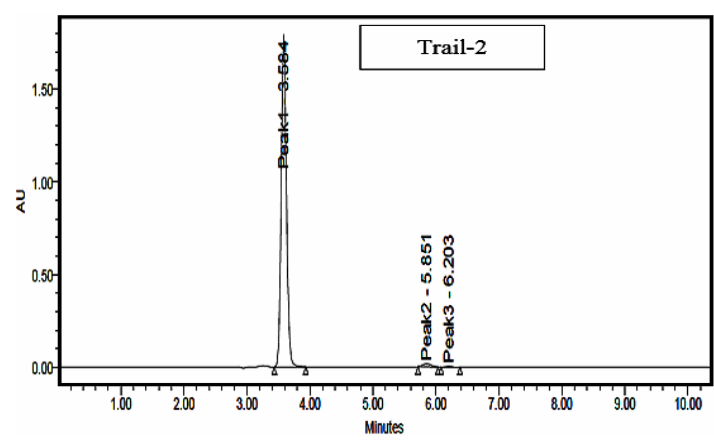

Fig. 4. representing chromatogram of development trial no. 1 to 4

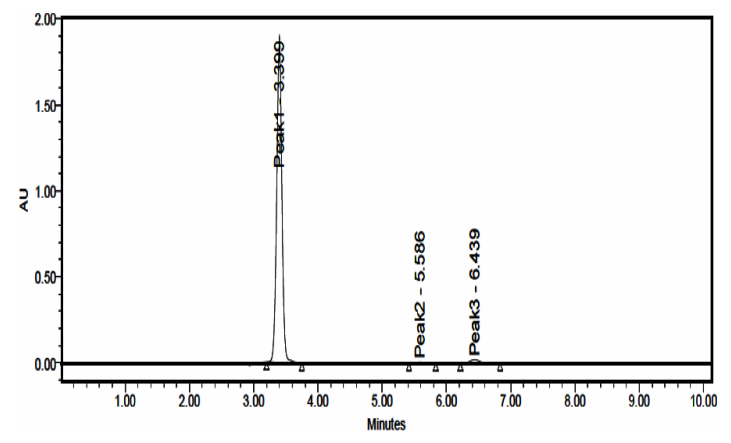

Fig. 5. representing chromatogram of development trial no. 5

\section{MATERIALS AND METHODS}

\section{Chemicals and Reagents}

Sitagliptin, metformin, empagliflozin standard and active pharmaceutical ingredients were received upon request from Fortune Pharma Lab., located at Hyderabad., India. The commercially 
available marketed drug product with the brand name Jardinance $10 \mathrm{mg}$ (Empagliflozin $10 \mathrm{mg}$ ) and Istamet tablet $50 \mathrm{mg} / 500 \mathrm{mg}$ of strength (Sitagliptin-50 $\mathrm{mg}$ drug substance and Metformin-500 mg drug substance) purchased from the nearby local medical store. All solvents, chemicals and required reagents indented for this research work were of highly pure chromatographic i.e., pure grade water, methanol, acetonitrile, and trifluoroacetic acid was procured, manufactured by Merck.

\section{Instrumentation}

A Waters manufactured HPLC system type of model 2695 having photodiode array detector, inbuilt autosampler injector with Empower-2 qualified software was used. Weighing instrument, sonicator bath, oven for drying purpose was used for the experiments.

\section{Chromatography of the method of analysis}

Resolution and separations for three drug components was achieved on the X-Bridge C18 column, $250 \mathrm{~mm}$ length with $4.6 \mathrm{~mm}$ internal diameter and $5 \mu \mathrm{m}$ of Particle Size. The mobile phase mixture utilized to achieve resolution and separation to calculate content determination was $0.1 \%$ Trifluoroacetic acid buffer $40 \%$ : methanol $40 \%$ : acetonitrile $20 \%$ at a flow of system $1.0 \mathrm{~mL} /$ minute and auto injection volume is $10 \mu \mathrm{L}$. The inbuilt column oven of the system was maintained at ambient temperature, and the drugs were subjected for detection at fixed wavelength of $224 \mathrm{~nm}$.

\section{Mobile phase of method of analysis}

Liquid mobile phase was prepared by inclusion and mixing $400 \mathrm{~mL}$ of $0.1 \%$ trifluoroacetic acid buffer, $400 \mathrm{~mL}$ methanol and $200 \mathrm{~mL}$ of acetonitrile (40:40:20\% ratio). The constituent mobile phase was subjected for sonication up to $15 \mathrm{~min}$ and filtered with filtration assembly by the use of $0.45 \mu \mathrm{m}$ membrane filter.

\section{Diluent in the method of analysis}

A composition of mixture in the volume 400 $\mathrm{mL} 0.1 \%$ trifluoroacetic acid buffer, $400 \mathrm{~mL}$ methanol and $200 \mathrm{~mL}$ of acetonitrile (40:40:20\% ratio) as a diluent in the method of analysis.

\section{Standard stock solution of method of analysis}

Precisely as well as carefully weighed, and transferred $50 \mathrm{mg}$ of sitagliptin standard, 500 $\mathrm{mg}$ metformin standard and $5 \mathrm{mg}$ of empagliflozin standard into a $50 \mathrm{~mL}$ previously dried and clean volumetric certified flask. Added a small quantity of diluent and subjected to sonication to dissolve the components in it completely and made volume of the flask up to the mark by diluent (1000 ppm of sitagliptin, 10000 ppm of metformin and 100 ppm of empagliflozin).

\section{Standard solution of method of analysis}

Further pipetted $2.5 \mathrm{~mL}$ of the above Sitagliptin, Metformin and Empagliflozin stock containing solution into $50 \mathrm{~mL}$ previously dried and clean volumetric certified flask and filled up to the line of flask with diluent. Mixed very well (50 ppm of sitagliptin, $500 \mathrm{ppm}$ of metformin and $5 \mathrm{ppm}$ of empagliflozin).

\section{Sample solution for assay method of analysis}

Step1: Accurately weighed 10 tablets of Jardinance $10 \mathrm{mg}$ (Empagliflozin $10 \mathrm{mg}$ ) formulation and crushed in mortar and pestle. Then transferred powder of tablet which is crushed, equivalent to the drug substance $10 \mathrm{mg}$ of empagliflozin into 100 $\mathrm{mL}$ previously dried and clean volumetric certified flask. Added the diluent mixture to about $70 \mathrm{~mL}$, and subjected to sonication for 30 min to extract the drug totally in the solution and made volume of the flask up to the line marked, with the diluent mixture. This solution was subjected to filtration through 0.45-micron PVDF type of syringe filter (100 ppm of empagliflozin, sample stock-1).

Step2: Precisely as well as carefully weighed 10 tablets of Istamet $50 \mathrm{mg} / 500 \mathrm{mg}$ (Sitagliptin-50 mg drug substance and Metformin-500 mg drug substance) formulation and crushed in mortar and pestle. Then transferred powder of tablet which is crushed, equivalent to the drug substance $50 \mathrm{mg}$ of sitagliptin and drug substance $500 \mathrm{mg}$ metformin into $50 \mathrm{~mL}$ previously dried and clean volumetric certified flask. Added the diluent mixture to about $35 \mathrm{~mL}$, and subjected to sonication for 30 min to extract both the drug completely in the solution and made volume of the flask up to the line marked, with the diluent mixture. This solution was subjected to filtration through 0.45-micron PVDF type of syringe filter (1000 ppm of sitagliptin \& 10000 ppm of metformin, sample stock -2).

Step3: Further pipetted $2.5 \mathrm{~mL}$ each of sample, stock-1 \& stock-2 and then transferred into 
$50 \mathrm{~mL}$ clean and previously dried volumetric certified flask and made volume of the flask up to the line marked, with the diluent mixture and mixed well (50 ppm of sitagliptin, 500 ppm of metformin and 5 ppm of empagliflozin).

Sample solution for content uniformity (the content of a single strength unit)

Step1: Accurately weighed one tablet of Jardinance $10 \mathrm{mg}$ (Empagliflozin $10 \mathrm{mg}$ ) formulation and transferred tablet into $100 \mathrm{~mL}$ previously dried and clean volumetric certified flask. Added the diluent mixture to about $70 \mathrm{~mL}$, and subjected to sonication for $30 \mathrm{~min}$ to extract the drug totally in the solution and made volume of the flask up to the line marked, with the diluent mixture. This solution was subjected to filtration through 0.45-micron PVDF type of syringe filter (100 ppm of empagliflozin, Sample stock-1).

Step2: Accurately weighed one tablet of Istamet $50 \mathrm{mg} / 500 \mathrm{mg}$ (Sitagliptin-50 mg drug substance and Metformin-500 mg drug substance) formulation and transferred into a $50 \mathrm{~mL}$ previously dried and clean volumetric certified flask. Added the diluent mixture to about $35 \mathrm{~mL}$, and subjected to sonication for $30 \mathrm{~min}$ to extract both the drug totally in the solution and made volume of the flask up to the line marked, with the diluent mixture. This solution was subjected to filtration through 0.45-micron PVDF type of syringe filter (1000 ppm of sitagliptin \& 10000 ppm of metformin, sample stock-2).

Step3: Further pipetted $2.5 \mathrm{~mL}$ each of sample, stock-1 \& stock-2 and then transferred into $50 \mathrm{~mL}$ clean and previously dried volumetric certified flask and made volume of the flask up to the line marked, with the diluent mixture and mixed well (50 ppm of sitagliptin, 500 ppm of metformin and 5 ppm of empagliflozin).

\section{Validation of chromatography method}

The optimized and developed chromatography method was subjected to perform the validity of the method as per the guidelines available from $\mathrm{ICH}$. The validation of the chromatography method was performed for system suitability, specificity of method, accuracy of method, precision of method, Intermediate precision of method, linearity of method, and robustness and detailed procedure is mentioned below with results.

\section{System Suitability of method of analysis}

The system suitability of method of analysis was confirmed by preparing and injecting standard solution of sitagliptin $(50 \mu \mathrm{g} / \mathrm{mL})$, metformin $(500 \mu \mathrm{g} /$ $\mathrm{mL})$, and empagliflozin ( $5 \mu \mathrm{g} / \mathrm{mL})$, and the solutions were subjected for injection into system six times and the parameters of chromatography like analyte retention time, analyte peak tailing, resolution between two components and USP criteria of plate count were noted.

\section{Specificity of method of analysis}

As mentioned in $\mathrm{ICH}$ stated guidelines, the term "Specificity" is the ability of the method of analysis to specifically separate or resolve the particular component or components of targeted drug substance analyte in the composition of other components or matrix.

\section{Linearity of method of analysis}

The stock solution containing standard of sitagliptin, metformin and empagliflozin, was made by using diluent mixture. From the stock solution containing standard, various levels of standard concentration solutions were made in the concentration range of $25-75 \mu \mathrm{g} / \mathrm{mL}, 250-750$ $\mu \mathrm{g} / \mathrm{mL}$ and 2.5-7.5 $\mu \mathrm{g} / \mathrm{mL}$ for sitagliptin, metformin and empagliflozin respectively and injected into chromatography system. The calibration plot of linearity (peak area of analyte vs. concentration of drug substance) were created in calculation sheet by using analysis results (from number of readings and sets are 3) at specified concentrations of drug substance. The linearity of the method was subjected for evaluation with the least square calculation method by using calculation sheet.

\section{Accuracy of method of analysis}

The accuracy for proposed method of analysis was determined with addition of standard at three different predefined concentrations of drug substance in the method at $50 \%, 100 \%$ as well as $150 \%$, and calculated for reporting purpose, the theoretical i.e., true value and found i.e., value obtained for comparison.

\section{Precision of method of analysis}

The precision for proposed method of analysis was confirmed from the peak area of drug substance, obtained by injecting six replicate samples prepared for sitagliptin $(50 \mu \mathrm{g} / \mathrm{mL})$, 
metformin (500 $\mu \mathrm{g} / \mathrm{mL})$, and empagliflozin $(5 \mu \mathrm{g} / \mathrm{mL})$. The intermediate precision of method of analysis was also carried out. The results obtained were calculated in calculation sheet for relative standard deviation i.e., \%RSD of method.

\section{Robustness method of analysis}

The Robustness of method of analysis was checked and confirmed by changing small however deliberately changing in method of analysis parameters like flow of system $( \pm 0.1 \mathrm{~mL} / \mathrm{min})$, organic phase ratio in composition of mobile phase $( \pm 10 \%$ of total volume). System suitability of method of analysis was checked.

\section{Degradation check in the method of analysis}

Specificity for method of analysis was confirmed by studying degradation in acid, base, peroxide, thermal, and UV stress conditions. The samples were exposed to the mentioned conditions and the peak obtained from the chromatography was checked for purity and demonstrated that the method is capable to resolve and separate all quantifiable degradation products in same chromatographic test method.

\section{Acidic condition study}

Further pipetted $2.5 \mathrm{~mL}$ each of sample stock-1 \& sample stock-2 (empagliflozin, sitagliptin \& metformin sample stock) and then transferred into a $50 \mathrm{~mL}$ clean and previously dried volumetric certified flask. Added $3.0 \mathrm{~mL}, 0.1 \mathrm{~N} \mathrm{HCl}$ and kept at room temperature for 24 hours. After $24 \mathrm{~h}$ refluxed for about $15 \mathrm{~min}$ at $60^{\circ} \mathrm{C}$ and allowed to cool at room temperature. This solution was subjected to neutralize with $3.0 \mathrm{~mL}, 0.1 \mathrm{~N} \mathrm{NaOH}$ and diluted up to the marked line with diluent mixture. As a final step, this solution was subjected to filtration through 0.45-micron PVDF type of syringe filter (50 ppm of sitagliptin, $500 \mathrm{ppm}$ of metformin and $5 \mathrm{ppm}$ of empagliflozin).

\section{Alkaline condition study}

Further pipetted $2.5 \mathrm{~mL}$ each of sample stock-1 \& sample stock-2 (empagliflozin, sitagliptin \& metformin sample stock) and then transferred into a $50 \mathrm{~mL}$ clean and previously dried volumetric certified flask. Added $3.0 \mathrm{~mL}, 0.1 \mathrm{~N} \mathrm{NaOH}$ and kept at room temperature for 24 hours. After $24 \mathrm{~h}$ refluxed for about $15 \mathrm{~min}$ at $60^{\circ} \mathrm{C}$ and allowed to cool at room temperature. This solution was subjected to neutralize with $3.0 \mathrm{~mL}, 0.1 \mathrm{~N} \mathrm{HCl}$ and diluted up to the marked line with diluent mixture. As a final step, this solution was subjected to filtration through 0.45-micron PVDF type of syringe filter (50 ppm of sitagliptin, $500 \mathrm{ppm}$ of metformin and $5 \mathrm{ppm}$ of empagliflozin).

\section{Oxidative degradation}

Further pipetted $2.5 \mathrm{~mL}$ each of sample stock-1 \& sample stock-2 (empagliflozin, sitagliptin \& metformin sample stock) and then transferred into a $50 \mathrm{~mL}$ clean and previously dried volumetric certified flask. Added $3 \mathrm{~mL} 1 \% \mathrm{H}_{2} \mathrm{O}_{2}$ solution and kept at room temperature for 24 hours. After $24 \mathrm{~h}$ diluted up to the mark with diluent. As a final step, this solution was subjected to filtration through 0.45 -micron PVDF type of syringe filter (50 ppm of sitagliptin, $500 \mathrm{ppm}$ of metformin and $5 \mathrm{ppm}$ of empagliflozin).

\section{Thermal degradation}

Sitagliptin, metformin and empagliflozin samples were placed in uniform way in petri plate and subjected for heating at $110^{\circ} \mathrm{C}$ (in oven) for 24 hours.

\section{Photolytic degradation}

The photostability nature of the drug substance in the drug product was studied by exposure of the sample to direct sunlight light up to 12 hours.

Further pipetted $2.5 \mathrm{~mL}$ each of sample, stock-1 \& stock-2 and then transferred into $50 \mathrm{~mL}$ clean and previously dried volumetric certified flask and made volume of the flask up to the line marked, with the diluent mixture and mixed well $(50 \mathrm{ppm}$ of sitagliptin, $500 \mathrm{ppm}$ of metformin and $5 \mathrm{ppm}$ of empagliflozin).

\section{Results and discussion for method validation parameters}

Validation of method of analysis is completed to show for its intended use and to establish quality characteristics of the developed method of analysis, meet the predefined acceptance of the targeted analytical test method. Validation of method of analysis was completed referring $\mathrm{ICH}$ 
published Q2 guideline. In this section, results of all parameters are tabulated and observations are noted.

\section{Suitability of method of analysis}

Suitability of method of analysis was achieved by evaluation of the parameters like tailing of analyte, theoretical plates, resolution between peaks, and \%RSD of injections from multiple injections. The values obtained, shows acceptable results and are tabulated in Tables 2, 3, 4 and 5. Chromatogram of standard solution is shown in Figure 6.

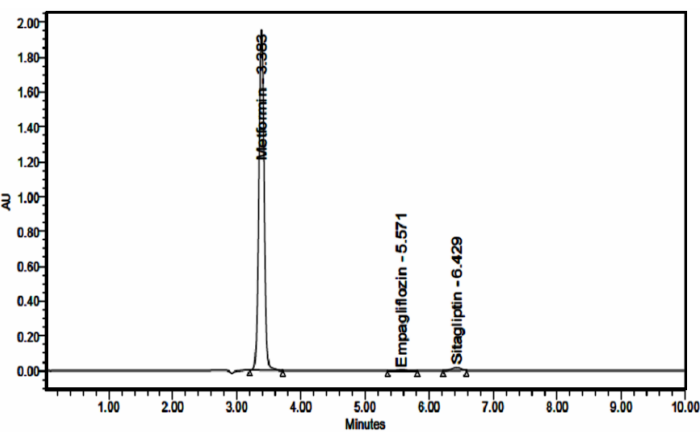

Fig. 6. Representing standard solution

Table 2: Results of system suitability from standard solution injection

No. Analyte name Concen-tration (ppm) Analyte Rt Analyte Area Analyte plate count Analyte Tailing Resolution between analytes

\begin{tabular}{llcccccc}
\hline 1 & Sitagliptin & 50 & 6.415 & 152877 & 10112 & 0.96 & NA \\
2 & Metformin & 500 & 3.383 & 10893692 & 8328 & 1.02 & 1.64 \\
3 & Empagliflozin & 5 & 5.564 & 32258 & 11141 & 1.06 & 12.11 \\
\hline
\end{tabular}

Table 3: Results of system suitability from standard solution injections for sitagliptin

\begin{tabular}{|c|c|c|c|c|c|}
\hline No. & Analyte Rt & Analyte Area & $\begin{array}{l}\text { Analyte name: Sitagliptin } \\
\text { Analyte plate count }\end{array}$ & Analyte Tailing & Resolution between analytes \\
\hline 1 & 6.415 & 152877 & 10112 & 0.96 & 3.64 \\
\hline 2 & 6.417 & 151496 & 10166 & 0.95 & 3.63 \\
\hline 3 & 6.421 & 159298 & 10172 & 0.95 & 3.65 \\
\hline 4 & 6.429 & 155765 & 10393 & 0.94 & 3.62 \\
\hline 5 & 6.430 & 155944 & 10530 & 0.93 & 3.62 \\
\hline 6 & 6.444 & 156039 & 10847 & 0.90 & 3.71 \\
\hline \multicolumn{2}{|c|}{ Mean } & 155236 & & & \\
\hline \multicolumn{2}{|c|}{ Std. Dev. } & 2737.9 & & & \\
\hline \multicolumn{2}{|c|}{$\%$ RSD } & 1.7 & & & \\
\hline
\end{tabular}

Table 4: Results of system suitability from standard solution injections for drug substance Metformin

\begin{tabular}{lcccc}
\hline & & \multicolumn{2}{c}{ Analyte name: Metformin } \\
No. & Analyte Rt & Analyte Area & Analyte plate count & Analyte Tailing \\
\hline 1 & 3.383 & 10893692 & 8328 & 1.02 \\
2 & 3.383 & 10919204 & 8273 & 1.02 \\
3 & 3.383 & 10879621 & 8224 & 1.01 \\
4 & 3.385 & 10886278 & 8212 & 1.02 \\
5 & 3.385 & 10883289 & 8344 & 1.02 \\
6 & 3.386 & 10916881 & 8586 & 1.04 \\
& & 10896494 & & \\
& Mean & & 65378965.3 & \\
& Std. Dev. & & 0.2 & \\
\hline
\end{tabular}

Table 5: Results of system suitability from standard solution injections for drug substance empagliflozin

\begin{tabular}{|c|c|c|c|c|c|c|}
\hline No. & & Analyte Rt & Analyte Area & $\begin{array}{l}\text { Analyte name: Empagliflozin } \\
\text { Analyte plate count }\end{array}$ & Analyte Tailing & Resolution between analytes \\
\hline 1 & & 5.564 & 32258 & 11141 & 1.06 & 12.11 \\
\hline 2 & & 5.565 & 32931 & 11308 & 1.04 & 12.22 \\
\hline 3 & & 5.568 & 32801 & 11291 & 1.06 & 12.18 \\
\hline 4 & & 5.571 & 32919 & 10870 & 1.03 & 11.91 \\
\hline 5 & & 5.578 & 33990 & 11213 & 1.04 & 12.07 \\
\hline \multirow[t]{4}{*}{6} & & 5.579 & 32507 & 11203 & 1.03 & 12.04 \\
\hline & Mean & 32901 & & & & \\
\hline & Std. Dev. & 594.7 & & & & \\
\hline & $\%$ RSD & 1.8 & & & & \\
\hline
\end{tabular}




\section{Specificity}

Any interfering peaks, from blank solution at retention times of sitagliptin, metformin and empagliflozin retention time are not observed in this method. Hence, this method was proved to be specific.

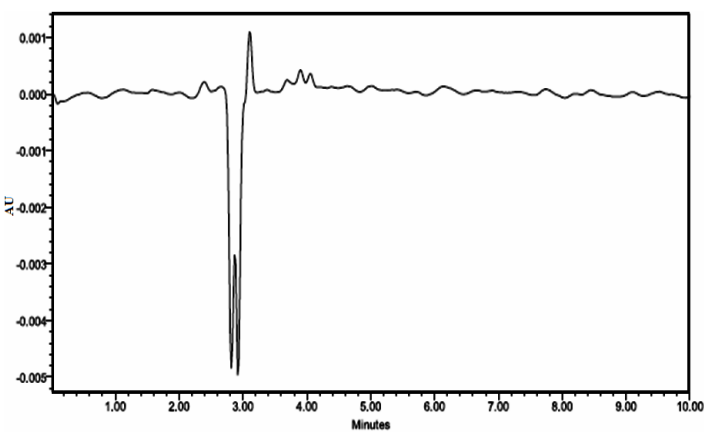

Fig. 7. representing blank (diluent)

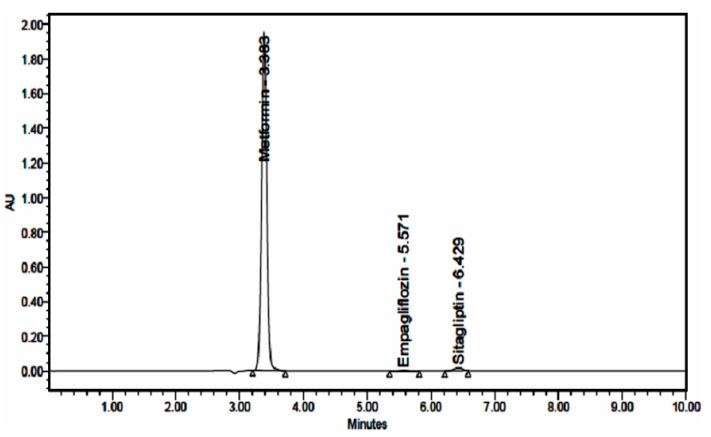

Fig. 8. Representing standard

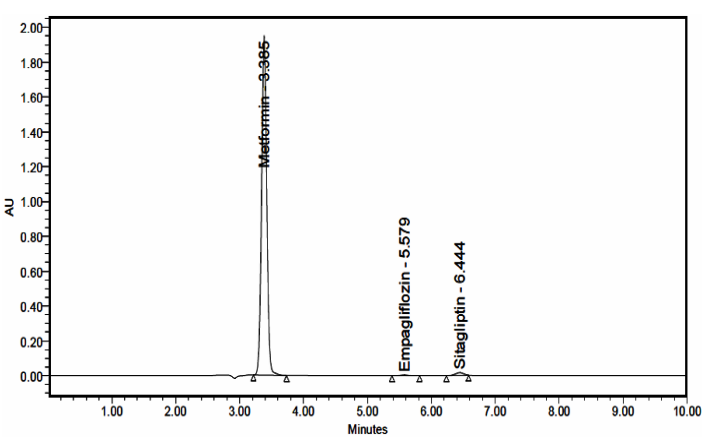

Fig. 9. representing sample

Retention times of metformin, empagliflozin, and sitagliptin, were 3.383, 5.571 and $6.429 \mathrm{~min}$ for standard solution and 3.385, 5.579 and 6.444 minutes for sample solution respectively.

\section{Linearity of method of analysis}

The linearity of method of analysis was subjected to evaluate at different range of concentration (50\% to $150 \%$ ) against standard level of sitagliptin, metformin and empagliflozin.

The calibration plot of linearity (peak area of analyte vs. concentration of drug substance in $\mu \mathrm{g} / \mathrm{mL}$ ) was created in calculation sheet by analysis results obtained (from number of reading and sets are 3) at specified concentration of drug substance. $R^{2}$ value for sitagliptin, metformin and empagliflozin was calculated and observed 0.9992, 0.9994 and 0.9997 respectively. The summary of the results, is tabulated in Tables 6, 7 \& 8 and shown in Figure. 10, 11, 12 \& 13.

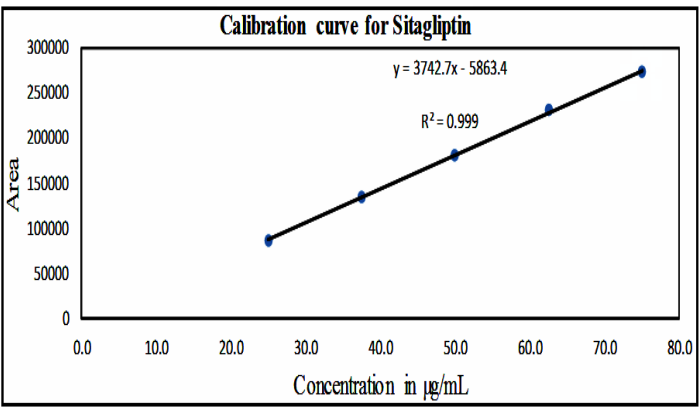

Fig. 10. Calibration Graph for Sitagliptin

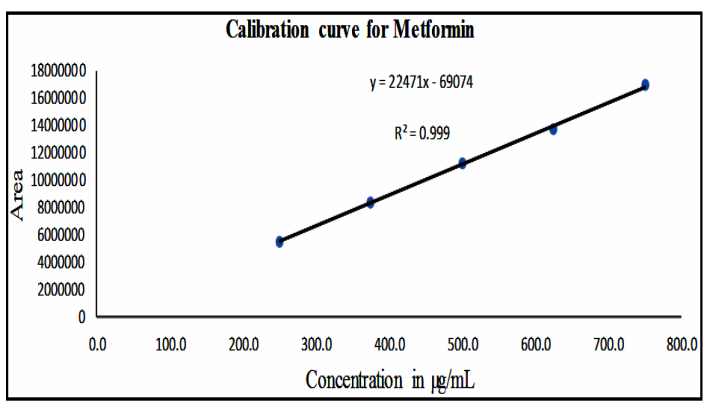

Fig. 11. Calibration Graph for Metformin

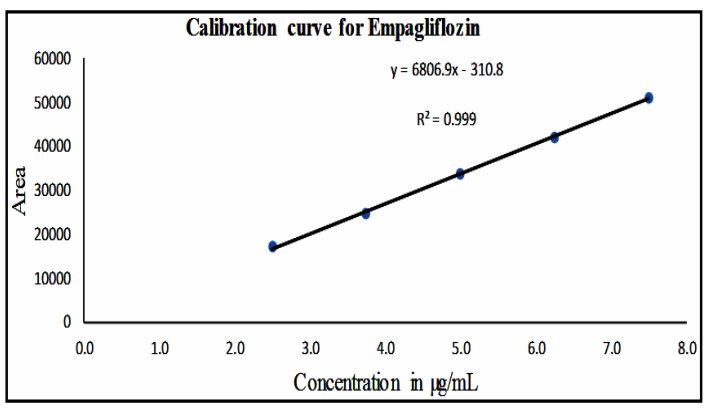

Fig. 12. Calibration Graph for Empagliflozin

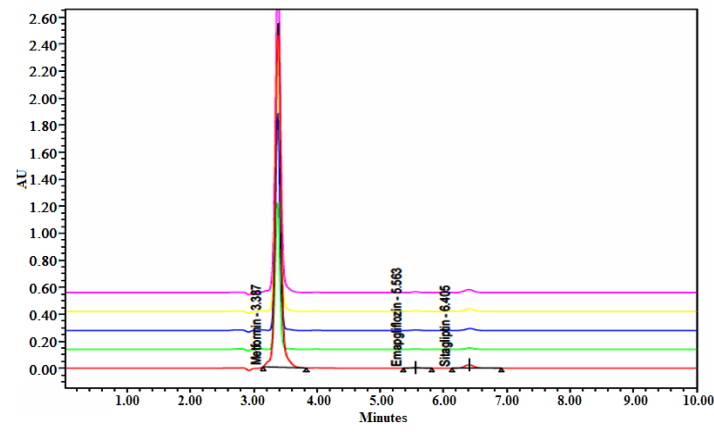

Fig. 13. Overlay of Linearity levels 
Table 6: Linearity results for sitagliptin

\begin{tabular}{|c|c|c|c|c|c|}
\hline S.No. & Linearity Level & Standard stock solution taken $(\mu \mathrm{L})$ & Diluted volume up to mark $(\mathrm{mL})$ & Concentration (ppm) & Area \\
\hline 1 & $50 \%$ & 1250 & 50 & 25.0 & 87438 \\
\hline 2 & $75 \%$ & 1875 & 50 & 37.5 & 134113 \\
\hline 3 & $100 \%$ & 2500 & 50 & 50.0 & 181266 \\
\hline 4 & $125 \%$ & 3125 & 50 & 62.5 & 230245 \\
\hline 5 & $150 \%$ & 3750 & 50 & 75.0 & 273289 \\
\hline & & & \multicolumn{2}{|c|}{ Correlation Coefficient } & 0.999 \\
\hline
\end{tabular}

Table 7: Linearity results for metformin

\begin{tabular}{|c|c|c|c|c|c|}
\hline S.No. & Linearity Level & Standard stock solution taken $(\mu \mathrm{L})$ & Diluted volume up to mark (mL) & Concentration (ppm) & Area \\
\hline 1 & $50 \%$ & 1250 & 50 & 250 & 5533712 \\
\hline 2 & $75 \%$ & 1875 & 50 & 375 & 8409615 \\
\hline 3 & $100 \%$ & 2500 & 50 & 500 & 11221992 \\
\hline 4 & $125 \%$ & 3125 & 50 & 625 & 13768045 \\
\hline 5 & $150 \%$ & 3750 & 50 & 750 & 16898907 \\
\hline \multicolumn{5}{|c|}{ Correlation Coefficient } & 0.999 \\
\hline
\end{tabular}

Table 8: Linearity results for empagliflozin

\begin{tabular}{ccccc}
\hline S.No. & Linearity Level & Standard stock solution taken $(\mu \mathrm{L})$ & Diluted volume up to mark $(\mathrm{mL})$ & Concentration $(\mathrm{ppm})$ \\
\hline 1 & $50 \%$ & 1250 & 50 & 2.5 \\
2 & $75 \%$ & 1875 & 50 & 3.8 \\
3 & $100 \%$ & 2500 & 50 & 5.0 \\
4 & $125 \%$ & 3125 & 50 & 6.3 \\
5 & $150 \%$ & 3750 & 50 & 7.5 \\
& & & Correlation Coefficient & 51070 \\
\hline
\end{tabular}

\section{Accuracy of method of analysis}

To check the accuracy of method of analysis, analysis was carried at three multiple levels,
$50 \%, 100 \%, 150 \%$. Percentage accuracy in terms of recovery was calculated, and the result values obtained are noted in Table as below 9, 10 and 11.

Table 9: Representing accuracy values, Sitagliptin

\begin{tabular}{ccccc}
\hline $\begin{array}{c}\text { Concentration in \% } \\
\text { (Specification Level) }\end{array}$ & Analyte Area & $\begin{array}{c}\text { Drug substance } \\
\text { Added }(\mathrm{ppm})\end{array}$ & $\begin{array}{c}\text { Drug substance } \\
\text { Amount obtained (ppm) }\end{array}$ & Recovery in \% \\
\hline $50 \%$ Set 1 & 78762 & 25.00 & 25.37 & 101.14 \\
$50 \%$ Set 2 & 78112 & 25.00 & 25.16 & 100.64 \\
$50 \%$ Set 3 & 78639 & 25.00 & 25.33 & 101.32 \\
$100 \%$ Set 1 & 159298 & 50.00 & 51.31 & 102.62 \\
$100 \%$ Set 2 & 155765 & 50.00 & 50.17 & 100.34 \\
$100 \%$ Set 3 & 155944 & 50.00 & 50.23 & 100.46 \\
$150 \%$ Set 1 & 233730 & 75.00 & 75.28 & 100.38 \\
$150 \%$ Set 2 & 233289 & 75.00 & 75.14 & 100.19 \\
$150 \%$ Set 3 & 235628 & 75.00 & 75.89 & 100.58 \\
\hline
\end{tabular}

Table 10: Representing accuracy results, Metformin

\begin{tabular}{ccccc}
\hline $\begin{array}{c}\text { Concentration in \% } \\
\text { (Specification Level) }\end{array}$ & Analyte Area & $\begin{array}{c}\text { Drug substance } \\
\text { Added (ppm) }\end{array}$ & $\begin{array}{c}\text { Drug substance } \\
\text { Amount obtained (ppm) }\end{array}$ & Recovery in \% \\
\hline $50 \%$ Set 1 & 5401809 & 250.00 & 247.87 & 99.49 \\
$50 \%$ Set 2 & 5426824 & 250.00 & 249.02 & 99.15 \\
$50 \%$ Set 3 & 5432191 & 250.00 & 249.26 & 99.61 \\
$100 \%$ Set 1 & 10919204 & 500.00 & 501.04 & 100.21 \\
$100 \%$ Set 2 & 10879621 & 500.00 & 499.23 & 99.85 \\
$100 \%$ Set 3 & 10916881 & 500.00 & 500.94 & 100.19 \\
$150 \%$ Set 1 & 16098907 & 750.00 & 738.72 & 98.50 \\
$150 \%$ Set 2 & 16055545 & 750.00 & 736.73 & 98.23 \\
$150 \%$ Set 3 & 16088046 & 750.00 & 738.22 & 98.39 \\
\hline
\end{tabular}


Table 11: Representing accuracy results, Empagliflozin

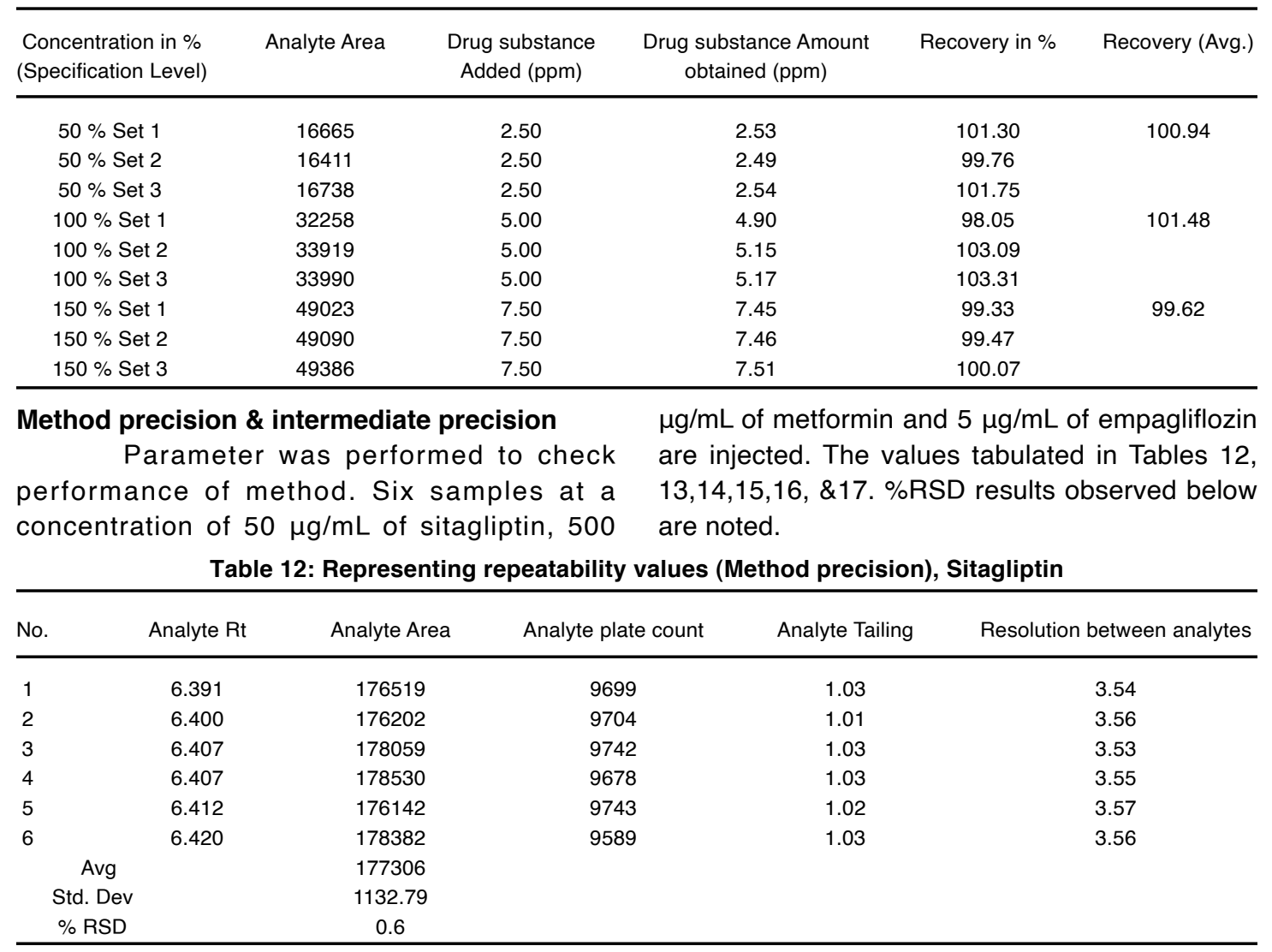

Table 13: Representing repeatability values (Method precision), Metformin

\begin{tabular}{|c|c|c|c|c|}
\hline No. & Analyte Rt & Analyte Area & Analyte plate count & Analyte Tailing \\
\hline 1 & 3.381 & 10884334 & 8594 & 1.02 \\
\hline 2 & 3.382 & 10990504 & 8500 & 1.02 \\
\hline 3 & 3.382 & 11000201 & 8461 & 1.02 \\
\hline 4 & 3.382 & 10989075 & 8515 & 1.03 \\
\hline 5 & 3.382 & 10926237 & 8566 & 1.02 \\
\hline 6 & 3.383 & 10952941 & 8519 & 1.03 \\
\hline \multicolumn{2}{|c|}{ Mean } & 10957215 & & \\
\hline \multicolumn{2}{|c|}{ Std. Dev } & 45300.24 & & \\
\hline \multicolumn{2}{|c|}{$\%$ RSD } & 0.4 & & \\
\hline
\end{tabular}

Table 14: Representing repeatability values (Method precision), Empagliflozin

\begin{tabular}{|c|c|c|c|c|c|}
\hline No. & Analyte Rt & Analyte Area & Analyte plate count & Analyte Tailing & Resolution between analytes \\
\hline 1 & 5.552 & 32186 & 11492 & 1.06 & 12.26 \\
\hline 2 & 5.555 & 32232 & 11698 & 1.05 & 12.16 \\
\hline 3 & 5.556 & 32493 & 11648 & 1.01 & 12.11 \\
\hline 4 & 5.559 & 32894 & 11549 & 1.04 & 12.07 \\
\hline 5 & 5.563 & 33063 & 11461 & 1.04 & 12.25 \\
\hline 6 & 5.568 & 33164 & 11186 & 1.07 & 12.21 \\
\hline \multicolumn{2}{|c|}{ Avg } & 32672 & & & \\
\hline \multicolumn{2}{|c|}{ Std. Dev } & 425.69 & & & \\
\hline \multicolumn{2}{|c|}{$\%$ RSD } & 1.3 & & & \\
\hline
\end{tabular}


Table 15: Representing repeatability values (Intermediate precision), Sitagliptin

\begin{tabular}{lccccc}
\hline No. & Analyte Rt & Analyte Area & Analyte plate count & Analyte Tailing & Resolution between analytes \\
\hline 1 & 6.415 & 152877 & 10112 & 0.96 & 3.64 \\
2 & 6.417 & 151496 & 10166 & 0.95 & 3.63 \\
3 & 6.421 & 159298 & 10172 & 0.95 & 3.65 \\
4 & 6.429 & 155765 & 10393 & 0.94 & 3.62 \\
5 & 6.430 & 155944 & 10530 & 0.90 & 3.71 \\
6 & 6.444 & 156039 & 10847 & & \\
& & 155236 & & & \\
& Avg & & 2737.9 & & \\
\end{tabular}

Table 16: Representing repeatability values (Intermediate precision), Metformin

\begin{tabular}{lcccc}
\hline No. & Analyte Rt & Analyte Area & Analyte plate count & Analyte Tailing \\
\hline 1 & 3.383 & 10893692 & 8328 & 1.02 \\
2 & 3.383 & 10919204 & 8273 & 1.02 \\
3 & 3.383 & 10879621 & 8224 & 1.01 \\
4 & 3.385 & 10886278 & 8212 & 1.02 \\
5 & 3.385 & 10883289 & 8344 & 1.02 \\
6 & 3.386 & 10916881 & 8586 & 1.04 \\
& & 10896494.2 & & \\
& Mean & & 17335.87 & \\
& Std. Dev & & 0.2 & \\
\hline
\end{tabular}

Table 17: Representing repeatability values (Intermediate precision), Empagliflozin

\begin{tabular}{cccccc}
\hline No. & Analyte Rt & Analyte Area & Analyte plate count & Analyte Tailing & Resolution between analytes \\
\hline 1 & 5.564 & 33258 & 11141 & 1.06 & 12.11 \\
2 & 5.565 & 33931 & 11308 & 1.04 & 12.22 \\
3 & 5.568 & 33801 & 11291 & 1.06 & 12.18 \\
4 & 5.571 & 33919 & 10870 & 1.03 & 11.91 \\
5 & 5.578 & 33990 & 11213 & 1.04 & 12.04 \\
6 & 5.579 & 33507 & 11203 & 1.03 & \\
& Avg & 33734 & & & \\
\multicolumn{2}{c}{ Std. Dev } & 290.23 & & & \\
\hline
\end{tabular}

\section{Robustness of method of analysis}

The robustness is studied to check, flow of system $( \pm 0.1 \mathrm{~mL} / \mathrm{min})$ and solvent mixture composition $( \pm 10 \%)$, and its effect on the area, tailing, and plate count. The results are tabulated in Tables 18, 19 \& 20.

Table 18: Representing robustness, Sitagliptin

\begin{tabular}{lccccc}
\hline Parameter evaluation & Analyte Area & Analyte Rt & Analyte plate count & Analyte Tailing Resolution between analytes \\
\hline Less Flow in the system, $0.9 \mathrm{~mL} / \mathrm{min}$ & 206052 & 7.103 & 10168 & 1.01 & 3.63 \\
Actual Flow in the system, $1.0 \mathrm{~mL} / \mathrm{min}$ & 152877 & 6.415 & 10112 & 0.96 & 3.64 \\
More Flow in the system, $1.1 \mathrm{~mL} / \mathrm{min}$ & 169796 & 5.833 & 9183 & 1.02 & 3.49 \\
Less organic phase & 205002 & 7.003 & 10158 & 1.01 & 3.61 \\
More organic phase & 168790 & 5.840 & 9145 & 1.02 & 3.42 \\
\hline
\end{tabular}

Table 19: Representing robustness, Metformin

\begin{tabular}{lcccc}
\hline Parameter evaluation & Analyte Area & Analyte Rt & Analyte plate count & Analyte Tailing \\
\hline Actual Flow rate of $0.9 \mathrm{~mL} / \mathrm{min}$ & 12619965 & 3.746 & 9160 & 1.03 \\
Less Flow rate of $1.0 \mathrm{~mL} / \mathrm{min}$ & 10893692 & 3.383 & 8238 & 1.02 \\
More Flow rate of $1.1 \mathrm{~mL} / \mathrm{min}$ & 10173220 & 3.078 & 8548 & 1.02 \\
Less organic phase & 12629865 & 3.741 & 9142 & 1.01 \\
More organic phase & 10172520 & 3.072 & 8531 & 1.02 \\
\hline
\end{tabular}


Table 20: Representing robustness, Empagliflozin

\begin{tabular}{lccccc}
\hline Parameter evaluation & Analyte Area & Analyte Rt & Analyte plate count & Analyte Tailing & Resolution between analytes \\
\hline Less Flow rate of $0.9 \mathrm{~mL} / \mathrm{min}$ & 39137 & 6.164 & 11774 & 1.02 & 12.38 \\
Actual Flow rate of $1.0 \mathrm{~mL} / \mathrm{min}$ & 32258 & 5.564 & 11141 & 1.06 & 12.11 \\
More Flow rate of $1.1 \mathrm{~mL} / \mathrm{min}$ & 30696 & 5.056 & 11089 & 0.98 & 11.96 \\
Less organic phase & 39047 & 6.154 & 11572 & 1.02 & 12.23 \\
More organic phase & 30196 & 5.013 & 11007 & 0.99 & 12.01 \\
\hline
\end{tabular}

All system suitability parameters are within the pre-defined acceptance criteria and there is no much shift in retention time for deliberately changed parameters as compared to the parameters in as such method. From the results obtained, it is proved method is robust.

\section{Degradation observations}

As no interference in blank and at degradant peaks, results showed purity of sitagliptin, metformin and empagliflozin drug substances, and hence method of analysis is specific and stability-indicating. The values are summarized in below Table 21.

Table 21: Representing values of forced degradation studies-sitagliptin, metformin \& empagliflozin

\begin{tabular}{|c|c|c|c|c|}
\hline Sr.No. & Stress parameter & Stress Condition & Degradation by Area \% & Peak Purity \\
\hline 1 & Standard & NA & NA & Passes \\
\hline 2 & Acidic & $0.1 \mathrm{~N}, \mathrm{HCl} 24$ hours & 0.19 & Passes \\
\hline 3 & Basic & $0.1 \mathrm{~N}, \mathrm{NaOH} 24$ hours & 1.60 & Passes \\
\hline 4 & Oxidative & $1 \%, \mathrm{H} 2 \mathrm{O} 224$ hours & 2.26 & Passes \\
\hline 5 & Thermal & $110^{\circ} \mathrm{C}, 24$ hours & 2.40 & Passes \\
\hline 6 & Photolytic & Sunlight, 12 hours & 2.69 & Passes \\
\hline
\end{tabular}

The three drug components, when exposed to above mentioned stress degradation conditions showed less degradation even for harsh degradation conditions and proved stability indicating nature to perform stability studies in the proposed method.

\section{Advantages}

Advantages of the new proposed, developed and validated method are, Other reported methods determine only assay, however our new method determines assay and content uniformity (content of single dosage unit). As assay and content of a single unit can be determined in a single analysis, correlation of result between content of sample matrix from the whole as well as a single unit can be determined. This data is useful in the evaluation of manufactured batches.

\section{CONCLUSION}

A new method of analysis with reverse phase chemistry was designed and developed to calculate assay and content uniformity of sitagliptin, metformin and empagliflozin pharmaceuticals. The method of analysis was validated for specified test parameters as mentioned in $\mathrm{ICH}$ published guidelines. From validation data and results obtained, it can be concluded that the target of developing a common chromatographic method for assay and content uniformity test has been achieved. This specific, economical, and efficient method can be used to estimate sitagliptin, metformin and empagliflozin as individual components as well as in combination in pharmaceuticals.

\section{ACKNOWLEDGEMENT}

The researchers express their thankfulness to Fortune Pharma Lab., located at Hyderabad, India for supplying samples.

\section{REFERENCES}

1. Garcia, P.; Buffoni, E.; Gomes, F.; Vilchez, J. Analytical Method Validation., 2011, DOI, $10.5772 / 21187$.

2. Erin, L.; Shannon, M.; Elizabeth, C. Pharmacy and Therapeutics., 2012, 37(12),699-708.

3. Uche, A.; Nicole, O.; Efrah, B.;Angie, T. Pharmacy and Therapeutics., 2015, 40(6), 364-368.

4. Gabor, S. HPLC in pharmaceutical Analysis., 1991, I,101-173. London: CRC Press.

5. Hobart, H.W.; Merritt L.L.; John, A.D. Instrumental Methods of Analysis,1998, $7^{\text {th }}$ Ed. 580-610.CBS Publishers, New Delhi. 
6. Sharma, B.K. Instrumental Method of Chemical Analysis, 2001, 20 th Ed., 54-83. Goel Publishing House, Meerut.

7. Kar, A. Pharmaceutical Drug Analysis., 2005, $2^{\text {nd }}$ Ed., 455-466. New Age International Publisher, New Delhi.

8. Snyder, L.R.; Kirkland, J.L.; Glajch, J.L. Practical HPLC Method Development., 1997, $3^{\text {rd }}$ Ed., 227. Wiley, New York.

9. Skoog, D.A.; West, D.M. Principles of Instrumental Analysis., 1980, $2^{\text {nd }}$ Ed., 674675, 690-696. Saunders Golden Sunburst Series, Philadelphia.

10. Validation of Analytical Procedure: Text and Methodology, Q2(R1). ICH Guidelines, 2005.

11. Basak, M.; Gouru S.R.; Bera A.; Nagappan, K.V. International Journal of Applied Pharmaceutics., 2019, 11(5), 60-65.

12. Sridevi, M.P.; Kumar, H.T.; Rao, S.Y.; Rao, V.P. Asian J. Pharm. Tech., 2018, 9(3), 208-211.
13. Lavanya, R.; Yunoos, Md. J. Adv. Pharm. Edu. \& Res., 2013, 3(4), 475- 479.

14. Kar, M.; Choudhury, P.K. Indian journal of pharmaceutical sciences., 2009, 71, 318-320.

15. Vinay, K.D.; Seshagiri, R. J. International Research Journal of Pharmacy and Medical Sciences (IRJPMS)., 2018, 1(5), 16-22.

16. Patel, A.M.; Chaudhary, A.B. World Journal of Pharmacy and Pharmaceutical Sciences., 2017, 6(9), 872-885.

17. Odela, M; Manohar, K. R. International journal of science \& research methodology., 2020, 15(1), 110-121.

18. Bhende, S.D.; Varanasi, M.B.; Abbulu, K; Swetha, M.D.; Shravanthi, V.; Kumari, J.K.; Shayamala, T. Orient. J. Chem., 2012, 28(1), 463-469.

19. Adsul, S.; Bidkar, J.; Harer, S.; Dama, G. International Journal of Chem Tech Research., 2018, 11, 428-435. 